\section{Providing unbiased IR spectra on Mars: the ground calibration of the infrared spectrometer onboard Perseverance rover}

\author{
CLÉMENT ROYER ${ }^{1}$, THIERRY FOUCHET ${ }^{1}$, OLIVIER $^{2}$
} FORNI $^{2}$, JEFFREY R JOHNSON ${ }^{3}$, OLIVIER GASNAULT ${ }^{2}$, PROF. CATHY QUANTIN-NATAF ${ }^{4}$, PIERRE BECK ${ }^{5}$, ANN $^{2}$ M OLLILA $^{6}$, LUCIA MANDON ${ }^{1}$, FRANCOIS POULET ${ }^{7}$, CÉDRIC PILORGET $^{7}$, PERNELLE BERNARDI ${ }^{1}$, JEANMICHEL REESS ${ }^{1}$, RAYMOND T NEWELL ${ }^{6}$, SYLVESTRE MAURICE $^{2}$ AND ROGER WIENS ${ }^{6}$

${ }^{1}$ LESIA

${ }^{2}$ IRAP

${ }^{3}$ JHU APL

${ }^{4}$ LGL-TPE, Univ. Lyon

${ }^{5}$ IPAG

${ }^{6}$ LANL

${ }^{7}$ IAS

Presenting Author: clement.royer@obspm.fr

The Perseverance rover (Mars 2020 mission, NASA) is exploring the mineral diversity of the paleolake within Jezero crater and is searching for potential biosignatures and past habitability evidence. Amongst its science payload, the SuperCam instrument (LANL/USA and IRAP/France) plays a central role in the Mars habitability investigation by providing rapid, synergistic, fine-scale mineralogy, chemistry, and color imaging [1]. In particular, it carries the first near-infrared spectrometer, IRS, to be operated on the Martian surface. IRS is a miniaturized point spectrometer (1.15 mrad field of view) located in the SuperCam's mast unit. Its spectral range (1.3 - 2.6 $\mu \mathrm{m}$ range) covers major silicate and hydrated mineral absorption features [2].

Mineral identifications are performed by analyzing the position and shape of their absorption bands and the determination of the abundances of the mixture requires a good knowledge of the absolute reflectance value. During the operations in Jezero, reflectance spectra are derived from instrument data by dividing by the ambient illumination spectrum and using an atmospheric correction process [3, 4]. IRS spectral data are strongly dependent on the instrument's response which potential artifacts can lead to the apparition of features similar to absorption bands, the band shape and depth ratio alteration, and the general spectral slope change (Fig. 1).

Even though the instrument has been fully calibrated on ground before its launch [5], we propose a flight calibration campaign to check its transfer function and validate the data reduction process. This campaign aims to cover the operation parameters range in terms of illumination and temperature and suggests a calibration follow up all along the mission, with regular Calibration Targets measurements. We will here present this calibration campaign and the consequences of an instrument residual on science interpretation.

[1] Wiens, R.C. et al., 2017. Spectroscopy; [2] Fouchet et al., 2015, 46 ${ }^{\text {th }}$ LPSC; [3] Maurice et al., this conference; [4] Mandon et al., this conference; [5] Royer et al., 2020, RScI;
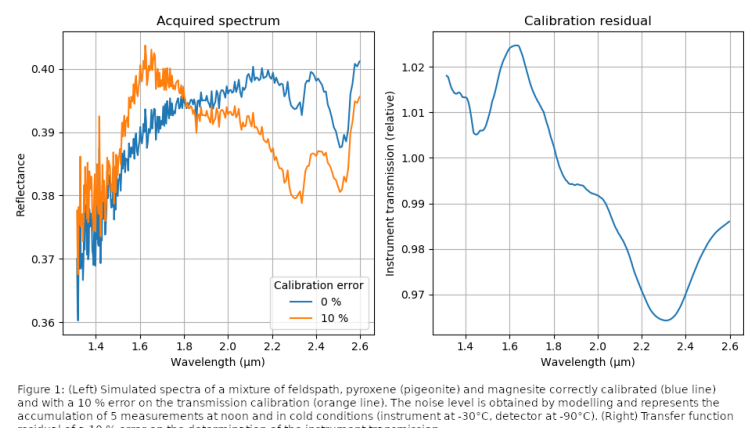